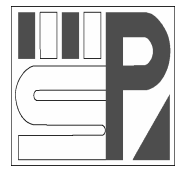

Science Press
Journal of Arid Land

2012, 4(1): 36-42

doi: 10.3724/SP.J.1227.2012.00036

jal.xjegi.com; www.chinasciencejournal.com

\title{
Comparison of seed germination of four Artemisia species (Asteraceae) in northeastern Inner Mongolia, China
}

\author{
XueHua $\mathrm{LI}^{1 *}$, DeMing JIANG ${ }^{1}$, Alamusa ${ }^{1}$, QuanLai ZHOU ${ }^{1}$, Toshio OSHIDA ${ }^{2}$ \\ ${ }^{1}$ Institute of Applied Ecology, Chinese Academy of Sciences, Shenyang 110016, China; \\ ${ }^{2}$ Azabu University, Sagamihara 252-5201, Japan
}

\begin{abstract}
Two psammophile-dominated Artemisia semi-shrubs ( $A$. wudanica and $A$. halodendron) and two annual Artemisia forbs (A. sieversiana and A. scoparia) bear significant ecological functions in Horqin Sandy Land, but systematical information on their achenes' germination is very limited. A set of studies were conducted to evaluate seed germination responses to storage periods and methods, different temperatures, lights conditions and sand burial depths, in order to determine inter-specific germination variation in the same genus and to explain how the species adapt to its microhabitat. Fresh achenes of $A$. wudanica, $A$. halodendron and $A$. sieversiana showed high germination capacities, but those of $A$. scoparia had obvious innate dormancy, which could be broken by chilling and dry storage, especially long-term dry storage. Achene germination of the two semi-shrubs preferred lower temperature fluctuation $\left(10\right.$ to $22^{\circ} \mathrm{C}$ ) and was not sensitive to light. But the two annuals preferred higher temperature fluctuation $\left(34\right.$ to $\left.22^{\circ} \mathrm{C}\right)$ and strong light for their achene germination. These four Artemisia species showed similar responses to sand burial, i.e. soil surface was most favorable for seedling emergence, and the deeper the sand burial, the fewer the seedling emergence. For the two semi-shrubs, their microhabitats are sand dunes with high temperature and intense light, which are not favorable for germination and seedling survival. Only rainfall contributes to temporary decrease of temperature and then triggers germination. We deduced that germination is not the main but a supplementary reproductive mode for the two semi-shrubs in sand dunes. For the two annuals, achene germination is the only reproductive mode, but different responses have been developed for microhabitat adaptation. For $A$. sieversiana, high germination capacities in wide temperature ranges and all light conditions could improve its competition and advancement in the wettest microhabitats. For $A$. scoparia, obvious innate dormancy of fresh achenes and germination inhabitation under unfavorable conditions are important adaptation to environmental disturbances.
\end{abstract}

Keywords: annuals; semi-shrubs; Artemisia species; germination; chilling and dry storage; light; temperature; sand burial

The genus Artemisia (Asteraceae) includes more than 500 species that mainly inhabit temperate regions of Europe, Asia and America. There are about $200 \mathrm{Ar}$ temisia species in China, among which 51 were found in arid and semi-arid desert areas (Liu, 1992). The Horqin Sandy Land, located in the temperate semi-arid steppe zone of northeastern China, is the main distribution region of many Artemisia species. The endemic Artemisia wudanica is a dominant semi-shrub growing in the mobile and semi-mobile sand dunes (Jin and Ye, 1989). Artemisia halodendron mainly inhabits semi- fixed sand dunes ( $\mathrm{Li}, 1991)$. These two semi-shrubs are psammophile-dominated plants and play an important role in sand dune stabilization. Artemisia scoparia is an annual or biennial forb with wide ecological amplitude and strong adaptation in desert areas, and can grow and reproduce under conditions of moderate disturbance (Zhang et al., 2002). Artemisia sieversiana is an annual forb and is inclined to inhabit at wettish environments (Liu, 1992).

Received 2011-08-29; accepted 2011-11-29

*Corresponding author: XueHua LI (E-mail: 1ixuehua@iae.ac.cn) 
Each desert plant has its own adaptation strategy that enables it to survive in certain severe environments (Gutterman, 1993). As an important part of plant life cycle, seed germination plays a key role in the dynamics of desert species (Tevis, 1958; Mott, 1974), and seed germination strategies have been studied systemically in many desert regions all over the world, with a special focus on annuals (Juhren et al., 1956; Beatley, 1974; Gutterman, 1993, 2000; Wang et al., 1998; Huang et al., 2001; Li et al., 2006). In previous studies, light, temperature and sand burial depth are the key factors to regulate seed germination in sandy areas. For example, the studies showed there are three kinds of germination responses to light: (1) seed could germinate well both in light and darkness (Baskin and Baskin, 1998); (2) seed germinates well only under light (Evenari and Gutterman, 1976; Huang and Gutterman, 2000); (3) seed germinates well under darkness (Koller, 1956; Baskin and Baskin, 1998). On the other hand, different species have their own optimal temperature ranges which are closely related with their microhabitats (Juhren et al., 1956; Gutterman and Evenari, 1994; Huang et al., 2001; Zhao et al., 2005; Li et al., 2006). Sand burial has important effects on seed germination and seedling survival, and seeds in deep sand layer could be dormant and form soil seed bank (Weller, 1985). Most species have showed different optimal sand burial depths because of seed morphological traits, but they also showed similar responses to sand burial, i.e., seed germination percentages could decrease with the increasing of sand burial depths (Chen and Maun, 1999; Huang et al., 2001; Zhao et al., 2005).

In Horqin Sandy Land, the species of Artemisia are widely used as pasture and medicine, as well as for sand stabilization to combat desertification and environmental deterioration (Liu, 1992; Jiang et al., 2002). Two semi-shrub species, $A$. wudanica and $A$. halodendron, and two annual species, $A$. scoparia and $A$. sieversiana, were researched in this study. Actually, the same genius species with different lifeforms and microhabitats facilitate comparative studies on seed germination to explain their common and special adaptabilities to sandy environments. Recently, some studies have explained the ecological adaptability of $A r$ temisia species to environmental uncertainty. For $A$. wudanica and A. halodendron, viability and germina- tion characteristics of canopy-stored seeds (Ma et al., 2010) and seedling growth variation in response to sand burial (Liu et al., 2008) have been studied. Germination characteristics of fresh, chilled and dry stored achenes of $A$. scoparia and A. sieversiana have been determined (Li et al., 2006). But comparative studies on seed germination under the same environmental conditions are still not considered systematically.

Here, we mainly compared seed germination of four Artemisia species in fresh collection, chilled storage (150 days), dry storage (150 days and 365 days, respectively) treatments in order to determine their different responses to storage methods. Then, we also studied ecophysiological responses of seed germination to different lights, temperatures and sand burial depths. The aims were to: (1) determine if there are interspecific variations in germination strategies within the genus Artemisia, especially for species with different life-forms; (2) clarify how germination strategies manifest their adaptability to different microhabitats.

\section{Materials and methods}

\subsection{Study area}

The study area is located at Ulan'aodu village $\left(43^{\circ} 02^{\prime} \mathrm{N}, 119^{\circ} 39^{\prime} \mathrm{E}\right.$; and $478 \mathrm{~m}$ asl $)$ in the southwestern Horqin Sandy Land, Inner Mongolia, China. The temperate climate in this semi-arid area is continental and monsoonal. The annual mean precipitation is $284 \mathrm{~mm}$ (1981-2004) with $70 \%$ occurring in the growing season (May-September), annual mean open-pan evaporation $1,549 \mathrm{~mm}$ and annual mean temperature $6.3^{\circ} \mathrm{C}$. Mean maximum temperature in the warmest month (July) is $23^{\circ} \mathrm{C}$, and mean minimum temperature in the coolest month (January) is $-14^{\circ} \mathrm{C}$. During the growing season (May to September), daily temperatures oscillate in the range of $10^{\circ} \mathrm{C}$ to $35^{\circ} \mathrm{C}$. The annual mean wind velocity is $4.4 \mathrm{~m} / \mathrm{s}$, and the number of gale days $(>17 \mathrm{~m} / \mathrm{s})$ is 21-80 days.

\subsection{Achenes collection and storage}

Mature achenes of four Artemisia species were collected directly from plants in the western region of Horqin Sandy Land in October 2003. After the collection, achenes were cleaned and then placed in paper 
bags in darkness at the laboratory $\left(15-20^{\circ} \mathrm{C}\right)$ until different treatments were determined later.

\subsection{Germination experiments}

From November 2003 to November 2004, a series of germination experiments were conducted. In each treatment, a group of $5 \times 50$ achenes of each for the four species were placed on filter paper in $90 \mathrm{~mm}$ Petri dishes, moistened with distilled water and transferred to germination chambers with different light and temperature conditions. Each dish was inspected daily, and germinated achenes were counted and removed. Germination was defined as radicle emergence (Bewley and Black, 1994).

\subsubsection{Freshly collected achenes}

In November 2003, the germination capacity of freshly collected achenes was tested. The germination chamber provided visible radiation of $9000 \mathrm{Lx}$, over a 15 -h day at $28^{\circ} \mathrm{C}$ and dark, over a 9-h night at $16^{\circ} \mathrm{C}$, average daily maximum and minimum temperature at a soil depth of $2-5 \mathrm{~cm}$ during the growing season from May to September. The minimum duration of treatment was 30 days, and counting germinable seeds continued until no germination occurred for 5 successive days.

\subsubsection{Chilling and dry storage of achenes}

In November 2003, 500 achenes of each species were placed in cloth-bags and buried in soil of $2-5 \mathrm{~cm}$ for chilling at Ulan'aodu station, because soil temperature measured at this depth was in the range of $-10^{\circ} \mathrm{C}$ to $0.5^{\circ} \mathrm{C}$. In April 2004, a part of achenes were taken out from laboratory and field respectively, and experiments were conducted to test the germination responses of achenes to 150 days' chilling and dry storage, respectively. In November 2004, some achenes were taken out from laboratory, and experiments were conducted to test the germination capacity and the longevity of achenes after dry storage for one year. These germination experiments were all done under the same conditions as described in fresh achenes treatments.

\subsubsection{Response to light}

In October 2004, achenes were placed under three light conditions in laboratory: continuous high light (9000 Lx), low light (2200 Lx) and darkness. Germi- nated achenes in high light and low light conditions were recorded and removed every day. Germinated achenes in darkness were recorded when the treatment was terminated. The experiments were carried out under a constant temperature of $22^{\circ} \mathrm{C}$ for 20 days.

\subsubsection{Response to temperature}

In December 2004, achenes were respectively placed at $10,16,22,28$ and $34^{\circ} \mathrm{C}$ under continuous low light (2200 Lx) for 20 days. When all experiments ended, ungerminated achenes at $10^{\circ} \mathrm{C}$ to $34^{\circ} \mathrm{C}$ were placed at $22^{\circ} \mathrm{C}$ for 10 days to determine if non-germination was due to high or low temperature.

\subsubsection{Response to sand burial}

In July 2004, a group of $5 \times 50$ achenes of each species were placed on the surface and at depths of 1,2,3 and $5 \mathrm{~cm}$ in sandy soil in plastic pots $(20 \mathrm{~cm}$ in diameter, $20 \mathrm{~cm}$ high) at Ulan'aodu station. Each pot was irrigated to ensure that germination was not limited due to water stress. The irrigation time interval was about 2 days, but it was prolonged or shortened based on actual rainfall. Each pot was inspected daily, and seedlings were counted and removed. The experiments lasted for 20 days.

\subsection{Data analysis}

The results of all germination tests are presented as germination percentages or emergence seedling percentages ( \pm S.E.). All data were log-transformed and analyzed using the SPSS program for windows Version 10.0. A one-way analysis of variance (ANOVA) and Least Significant Difference (LSD) tests were performed to determine the significance of seed germination or emergence seedling percentage under each treatment.

\section{Results}

\subsection{Germination of freshly collected, chilled and dry stored achenes}

For freshly collected achenes, germination percentages of A. sieversiana, A. wudanica and A. halodendron were $99.6 \%, 96.6 \%$ and $88.0 \%$, respectively, but that of A. scoparia was only $54.8 \%$ (Fig. 1). For chilled and dry stored achenes, germination percentages of $A$. wudanica, A. sieversiana and $A$. halodendron were all more than $90 \%$. Germination percentages of chilled and dry stored achenes of A.scoparia were signifiantly 
higher than that of fresh achenes, and germination percentage of dry stored achenes was significantly higher than that of chilled achenes. Germination percentage of achenes stored dry for 365 days was significantly higher than that of those stored dry for 150 days (Fig. 1).

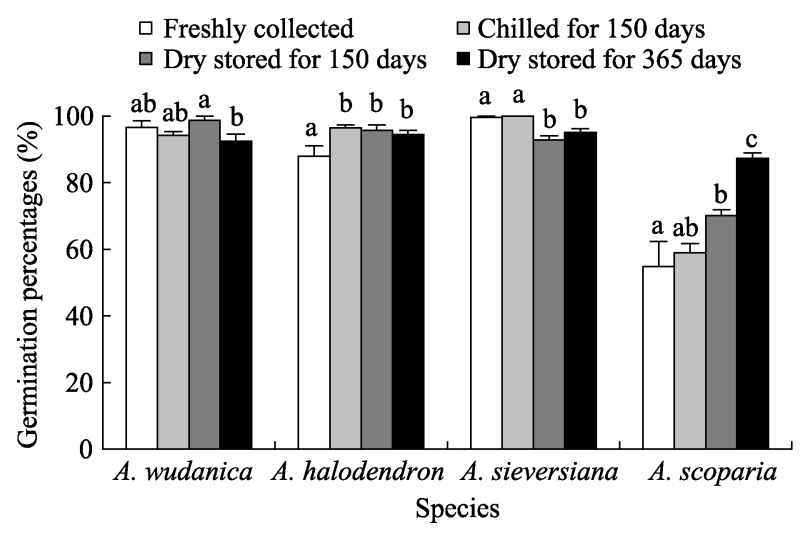

Fig. 1 Germination percentages of freshly, chilled and dry stored achenes for four Artemisia species. Different letters mean germination percentages of seeds for a species in different storage treatments differed significantly at $P<0.05$.

\subsection{Response to light}

A. wudanica, A. halodendron and A. sieversiana reached high final germination percentages $(>90 \%)$ in both high light and low light, which were significantly higher than that in darkness $(P<0.05)$. Germination percentages of $A$. scoparia were significantly different,
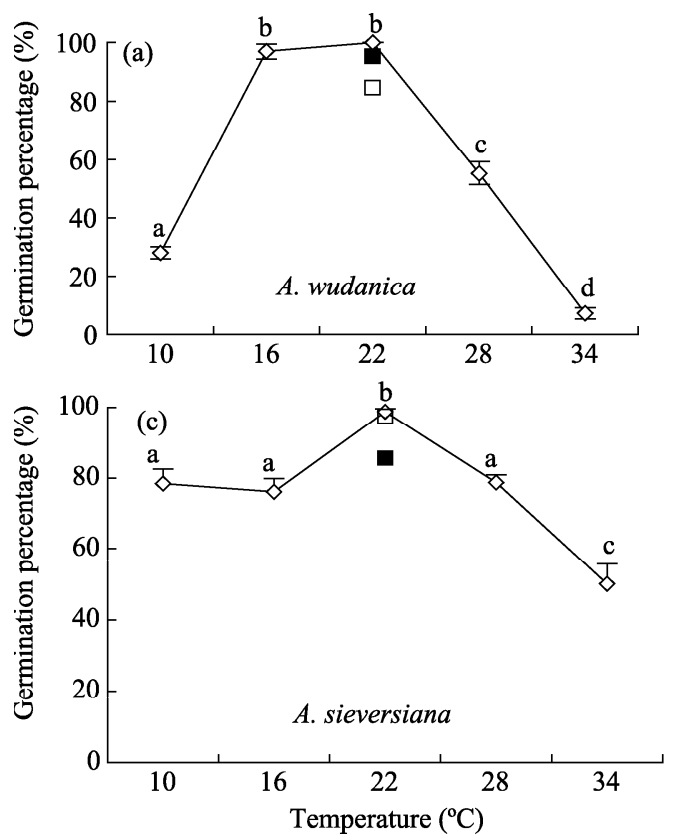

being $78 \%, 61.5 \%$ and $5.5 \%$, respectively, in low light, high light and darkness (Fig. 2).

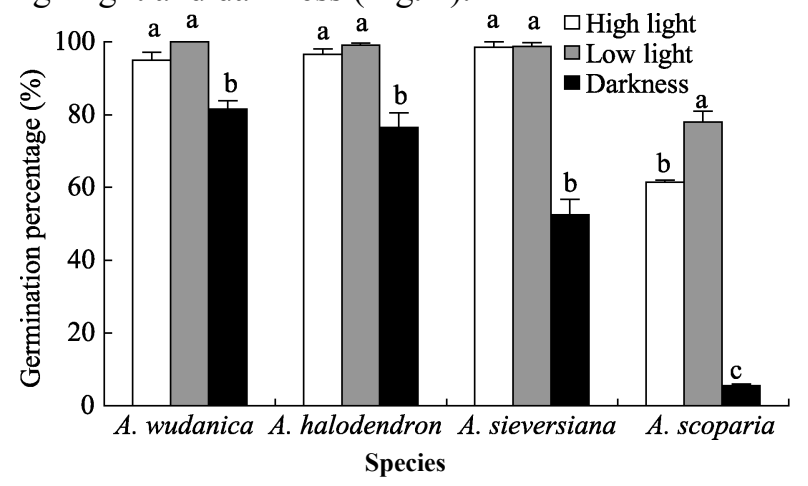

Fig. 2 Germination percentages of four Artemisia species under different light conditions. Different letters mean germination percentages of seeds for a species under different light conditions differed significantly at $P<0.05$.

\subsection{Response to temperature}

Achenes of the four Artemisia species germinated in a wide temperature range $\left(10-34^{\circ} \mathrm{C}\right)$, and all reached the highest germination percentages at $22^{\circ} \mathrm{C}$. However, higher $\left(34^{\circ} \mathrm{C}\right)$ and lower $\left(10^{\circ} \mathrm{C}\right)$ temperature (compared with temperature $22^{\circ} \mathrm{C}$ ) significantly reduced germination percentages, especially at $34^{\circ} \mathrm{C}$ (Fig. 3). With temperature changes $\left(10-22^{\circ} \mathrm{C}\right.$ and $\left.34-22^{\circ} \mathrm{C}\right)$, total germination percentages of achenes for the two semi-shrubs in $10-22^{\circ} \mathrm{C}$ were higher than those in $34-$
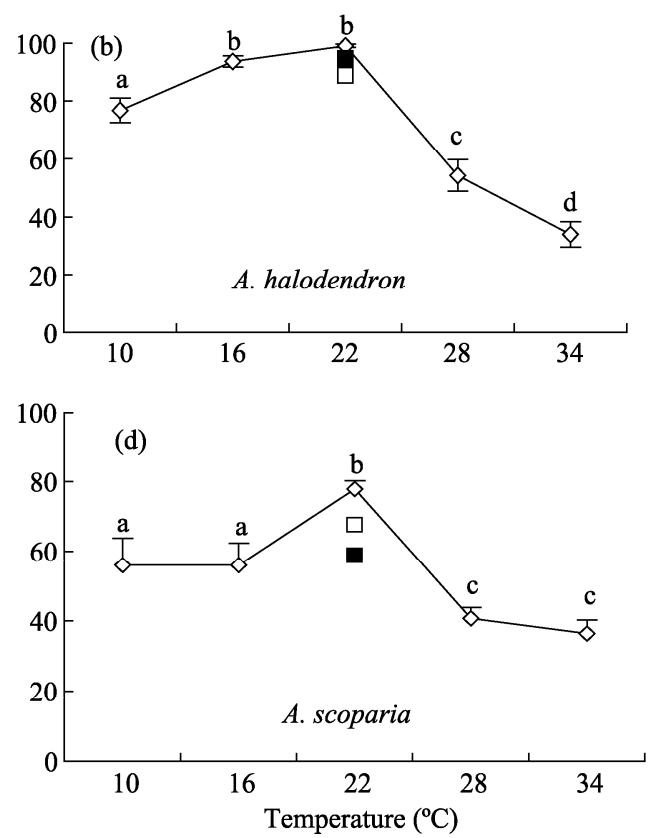

Fig. 3 Germination percentages of four Artemisia species under different temperatures. $\diamond$ means germination percentage under constant temperature (Means $\pm \mathrm{SE}$ ); - means final germination percentage under temperature change from $10-22^{\circ} \mathrm{C}$; $\square$ means final germination percentage under temperature change from $34-22^{\circ} \mathrm{C}$. Different letters mean that germination percentage of seeds for a species under different temperature conditions differed significantly at $P<0.05$. 
$22^{\circ} \mathrm{C}$, and total germination percentages of achenes for the two annuals in $34-22^{\circ} \mathrm{C}$ was significantly higher than those in $10-22^{\circ} \mathrm{C}$ (Fig. 3).

\subsection{Response to sand burial}

Seedling emergences in pots were lower than those in the laboratory. The highest seedling emergence of the four species appeared on the soil surface, and the deeper the achenes were placed in sand, the lower the percentages of seedling emergences. No seedlings emerged for achenes of $A$. scoparia buried at $2-\mathrm{cm}$ depth and for achenes of all the four species buried at 3-cm depth (Table 1).

Table 1 Seedling emergence percentages of four Artemisia species at different sand burial depths

\begin{tabular}{|c|c|c|c|c|}
\hline \multirow{2}{*}{$\begin{array}{c}\text { Depth } \\
(\mathrm{cm})\end{array}$} & \multicolumn{2}{|c|}{ A. wudanica A. halodendron } & A. sieversiana & A. scoparia \\
\hline & \multicolumn{4}{|c|}{$(\%)$} \\
\hline 0 & $73.3 \pm 8.35 \mathrm{a}$ & $50.7 \pm 3.53 \mathrm{a}$ & $78.0 \pm 4.62 \mathrm{a}$ & $48.0 \pm 4.16 \mathrm{a}$ \\
\hline 1 & $36.0 \pm 8.08 \mathrm{~b}$ & $41.3 \pm 7.51 b$ & $57.3 \pm 7.06 \mathrm{~b}$ & $5.33 \pm 3.33 b$ \\
\hline 2 & $24.0 \pm 3.06 \mathrm{c}$ & $20.2 \pm 2.00 \mathrm{c}$ & $24.7 \pm 3.33 \mathrm{c}$ & $0 \mathrm{c}$ \\
\hline 3 & $0 \mathrm{~d}$ & $0 \mathrm{~d}$ & $0 \mathrm{~d}$ & $0 \mathrm{c}$ \\
\hline
\end{tabular}

Note: Means \pm SE. Different letters means germination percentages of seeds for a species at different sand burial depths differed significantly at $P<0.05$.

\section{Discussion and conclusion}

Freshly collected achenes of $A$. wudanica, $A$. halodendron and $A$. sieversiana showed strong germination capacity; those of A. scoparia had obvious innate dormancy. Chilling or dry storage did not reduce germination capability of $A$. wudanica, $A$. halodendron, A. sieversiana, but significantly increased germination percentage of A. scoparia. Based on Grime (1981), chilling and dry storage could increase seed germination. Dry storage worked more effectively in breaking the dormancy of achenes of $A$. scoparia; the longer the dry storage period, the higher the germination percentage. Achenes of four Artemisia species could remain high viability and germination capability after dry storage for up to one year, which indicated that the achenes perhaps had longer persistence in soil, especially for $A$. scoparia in laboratorial study. But field studies need to be conducted to support this conclusion. Actually, previous studies have demonstrated that the achenes of A. scoparia had a more persistent seed bank (Zhao et al.S20014). germination responses of four Artemisia species to different environmental factors have been revealed. Achenes of the four species could germinate in a wide temperature range $\left(10-34^{\circ} \mathrm{C}\right)$, and reached the highest germination percentages at $22^{\circ} \mathrm{C}$. This temperature range perhaps allows them to germinate in the rainy season in Horqin Sandy Land. However, the temperature fluctuation from low to optimal $\left(10-22^{\circ} \mathrm{C}\right)$ is more favorable for germination of the two semi-shrubs and that from high to optimal $\left(34-22^{\circ} \mathrm{C}\right)$ is more favorable for the two annuals. Based on previous studies, some species can germinate to higher percentages in darkness than in light (Koller, 1956; Keren et al., 1974), but many species can germinate equally well in light and darkness (Baskin and Baskin, 1998). In our study, achenes of four Artemisia species could attain higher percentages in light than in darkness, and germination of the two annuals was more inhibited by darkness than that of the two semi-shrubs. In sand burial, achenes on the soil surface could germinate well and the seedlings could emerge well. But the deeper the achenes were placed in sand, the lower seedling emergence was. This germination response to sand burial was similar with studies on the same genius species (A. monosperma and $A$. ordosica) in different sandy areas (Huang and Gutterman, 1998, 1999a, b, 2000).

The different germination responses of the four $\mathrm{Ar}$ temisia species showed their adaptability to different microhabitats. A. wudanica, a semi-shrub and an endemic species in Horqin Sandy Land, mainly dominates mobile and semi-mobile sand dunes, whereas $A$. halodendron dominates semi-fixed sand dunes (Jin et al., 1989; Li, 1991). Achenes of the two semi-shrubs on soil surface could germinate well at a lower temperature range and under different light conditions when rainfall is sufficient. This is the reason why many seedlings of $A$. wudanica and $A$. halodendron can be found in the surroundings of maternal plants in mobile and semi-mobile sand dunes after a rain. However the characteristics of the soil surface on sand dunes are usually characterized by high temperature, intense light, drought and strong wind erosion or sand burial. A heavy rain can change the microclimate for a short time by reducing air temperature and supplying more moisture, but the surface soil may dry quickly owing to a high evaporation rate. Such conditions are favorable for germination of achenes on the sand sur- 
face, but are not favorable for seedling survival. This explains why the final survival rate of seedlings for the two semi-shrubs is very low in their natural microhabitats. We deduced that germination is only a supplement reproductive mode in favorable laboratorial conditions, while vegetative reproduction is a main mode for the two semi-shrubs in natural sand dunes.

The microhabitats of the annual species, $A$. sieversiana, such as irrigation channels and humid sand are usually the wettest habitats in the sandy land (Liu, 1992). These conditions favor germination, seedling survival and completion of the life cycle. In this study, achenes of $A$. sieversiana had a high germination capacity under most treatments, and only darkness, high temperature $\left(34^{\circ} \mathrm{C}\right)$ and deep sand burial inhibited germination to a certain extent. The rapid germination strategy of $A$. sieversiana is an important adaptive mechanism that increases the competitive advantage of this species in its microhabitats (Rice and DyEhenoictohabitats of the annual species $A$. scoparia are usually degraded meadows and farmlands in desert regions (Zhang et al., 2002). Fresh achenes of $A$. scoparia showed some innate dormancy, which could reduce the competitive advantage gained by early emergence and establishment (Ross and Harper, 1972;

\section{References}

Abul-Fatih H A, Bazzaz F A. 1979. The biology of Ambrosia trifida L. II . germination, emergence, growth and survival. New Phytologist, 83(3): 817-827.

Baskin C C, Baskin J M. 1998. Seeds, Ecology, Biogeography and Evolution of Dormancy and Germination. San Diego: Academic Press.

Beatley J C. 1974. Phenological events and their environmental triggers in Mojave Desert ecosystems. Ecology, 55(4): 856-863.

Bewley J D, Black M. 1994. Seeds: Physiology of Development and Germination, $2^{\text {nd }}$ ed. New York: Plenum Press.

Chen H, Maun M A. 1999. Effects of sand burial depth on seed germination and seedling emergence of Cirsium pitcheri. Plant Ecology, 140(1): 53-60.

Evenari M, Gutterman Y. 1976. Observations on the secondary succession of three plant communities in the Negev Desert, Israel. I . Artemisietum herbae-albae. In: Acques R. Hommage au Prof. P. Chouafd, Erudes de Biologie Vegetale. Paris: C.N.R.S.Gif syr Yvette.

Grime J P, Mason G, Curtis A V, et al. 1981. A comparative study of germination characteristics in a local flora. Journal of Ecology,
Abul-Fatih and Bazzaz, 1979; Rice and Dyer, 2001). After one-year dry storage, however, the achenes had a relatively higher germination percentage $(87.3 \%$ in 9 days) compared with fresh achenes (54.8\% in 61 days), which may help to increase its competitive advantage in its microhabitats. Especially, the production of achenes by $A$. scoparia is large enough (about 14,984 achenes/plant) to compensate for the shortage of germinated seeds and increase the competitive advantage in many microhabitats (Yan, 2005). In our study, the achenes of A. scoparia had obvious innate dormancy in the first growing season, even up to one-year dry storage. The germination delays beyond the first season could create an age structure within the belowground population of seeds and form a persistent soil seed bank (Kalisz, 1991). These characteristics perhaps could explain why the annual species $A$. scoparia has strong adaptability to be disturbed and a relatively broad distribution range in semi-arid regions (Liu, 1992).

\section{Acknowledgements}

This research was financially supported by the National Natural Science Foundation of China (41071187 and 40701097). We thank YongMing LUO and HongMei WANG for their assistance in seed collection and storage treatments.

69(3): 1017-1059.

Gutterman Y. 1993. Seed Germination in Desert Plants. Adaptations of Desert Organisms. Berlin: Springer.

Gutterman Y, Evenari M. 1994. The influences of amounts and distribution of irrigation during the hot and dry season on emergence and survival of some desert winter annual plants in the Negev Desert, Israel. Journal of Plant Sciences, 42(1): 1-14.

Gutterman Y. 2000. Environmental factors and survival strategies of annual plant species in the Negev Desert, Israel. Plant Species Biology, 15(2): 113-125.

Henderson C B, Petersen K E, Redak R A. 1988. Spatial and temporal patterns in the seed bank and vegetation of a desert grassland community. Journal of Ecology, 76(3): 717-728.

Huang Z Y, Gutterman Y. 1998. Artemisia monosperma achene germination in sand: effects of sand depth, sand water content, cyanobacterial sand crust and temperature. Journal of Arid Environments, 38(1): 27-43.

Huang Z Y, Gutterman Y. 1999a. Water absorption by mucilaginous achenes of Artemisia monosperma, floating and germination affected by salt concentration. Journal of Plant Sciences, 47(1): 
$27-34$.

Huang Z Y, Gutterman Y. 1999b. Influences of environments factors on achene germination of Artemisia sphaerocephala, a dominant semi-shrub occurring in the sandy desert areas of Northwest China. South African Journal of Botany, 65(3): 187-196.

Huang Z Y, Gutterman Y. 2000. Comparison of germination strategies of Artemisia ordosica with its two congeners from deserts of China and Israel. Acta Botanica Sinica, 42(1): 71-80.

Huang Z Y, Gutterman Y, Hu H Z, et al. 2001. Seed germination in Artemisia Sphaerocephala. II. The influence of environmental factors. Acta Phytoecologica Sinica, 25(2): 240-246.

Jiang D M, Liu Z M, Kou Z W. 2002. Prospect of the study on desertification and its restoration of Horqin Sandy Land. Chinese Journal of Applied Ecology, 13(12): 1695-1698.

Jin Z C, Ye Z H. 1989. Pioneering sand binder-Artemisia wudanica. Jilin Forestry Sciences and Technology, 80(3): 11-13.

Juhren M, Went F W, Philipps E. 1956. Ecology of desert plants. IV. Combined field and laboratory work on germination of annuals in the Joshua Tree National Monument, California. Ecology, 37(2): 318-330.

Kalisz S. 1991. Experimental determination of seed bank age structure in the winter annual Collinsia verna. Ecology, 72(2): 575-585.

Keren A, Evenari M. 1974. Some ecological aspects of distribution and germination of Pancratium maritimum L. Israel Journal of Botany, 23: $202-215$.

Koller D. 1956. Germination-regulating mechanisms in desert seeds. III. Calligonum comosum L'her. Ecology, 37(3): 430-433.

Li J. 1991. The distribution of Artemisia halodendron and its status in the natural vegetation succession. Journal of Desert Research, 11(2): $55-60$.

Li X H, Li X L, Jiang D M, et al. 2006. Germination strategies and patterns of annual species in the temperate semiarid region of China. Arid Land Research and Management, 20(3): 195-207.

Liu B, Liu Z M, Guan D X. 2008. Seedling growth variation in response to sand burial in four Artemisia species from different habitats in the semi-arid dune field. Trees, 22(1): 41-47.
Liu Y X. 1992. Flora in Desertis Reipublicae Populorum Sinarum. Tomus 3. Beijing: Science Press.

Ma J L, Liu Z M, Zeng D H, et al. 2010. Aerial seed bank in Artemisia species: how it responds to sand mobility. Trees, 24(3): 435-441.

Mott J J. 1974. Factors affecting seed germination in three annual species from an arid region of western Australia. Journal of Ecology, 62(3): 699-709.

Rice K J, Dyer A R. 2001. Seed aging, delayed germination and reduced competitive ability in Bromus tectorum. Plant Ecology, 155(2): 237-243.

Ross M A, Harper J L. 1972. Occupation of biological space during seedling establishment. Journal of Ecology, 60(1): 77-88.

Tevis L Jr. 1958. Germination and growth of ephemerals induced by sprinkling a sandy desert. Ecology, 39(4): 681-688.

Thompson K, Band S R, Hodgson J G. 1993. Seed size and shape predict persistence in soil. Functional Ecology, 7(2): 236-241.

Wang Z L, Wang G, Liu X M. 1998. Germination strategy of the temperate sandy desert annual chenopod Agriophyllum squarrosum. Journal of Arid Environments, 40(1): 69-76.

Weller S G. 1985. Establishment of Lithospermum caroliniense on sand dunes: the role of nutlet mass. Ecology, 66(6): 1893-1901.

Yan Q L, Liu Z M, Li R P, et al. 2005. Relationship of seed production, seed morphology and life form of plant species. Acta Prataculturae Sinica, 14(4): 21-28.

Zhao W Z, Bai S M. 2001. Characteristics of seed bank at fenced grassland in Horqin Sandy Land. Journal of Desert Research, 21(2): 204-208.

Zhao L Y, Li F R, Zhang H, et al. 2004. Characteristics of the soil seed bank at the fenced sandy meadow in Horqin Sandy Land. Chinese Journal of Ecology, 23(2): 45-49.

Zhao X Y, Ren J Z, Wang Y R, et al. 2005. Germination responses to temperature and moisture in seed from three species of Caragana. Acta Botanica Boreali-Occidentalia Sinica, 25(2): 211-217.

Zhang B T, Wang D L, Yang Y F. 2002. Study on the biological characteristics and biomass dynamics of Artemisia Scoparia. Grassland of China, 24(1): 13-17. 